\title{
Progresso genético do melhoramento de arroz de terras altas no período de 1950 a 2001
}

\author{
Moacil Alves de Souza(1), Orlando Peixoto de Morais ${ }^{(2)}$, Roberto Evaristo Celi Herán(1), \\ Adeliano Cargnin ${ }^{(1)}$ e Adérico Júnior Badaró Pimentel ${ }^{(1)}$
}

\begin{abstract}
(1)Universidade Federal de Viçosa, Dep. de Fitotecnia, Av. P.H. Rolfs, s/no, CEP 36571-000 Viçosa, MG. E-mail: moacil@ufv.br, adelianoc@hotmail.com, adericopimentelufv@yahoo.com.br (2)Embrapa Arroz e Feijão, Caixa Postal 179, CEP 75375-000 Santo Antônio de Goiás, GO. E-mail: peixoto@cnpaf.embrapa.br
\end{abstract}

\begin{abstract}
Resumo - O objetivo deste trabalho foi quantificar o progresso genético obtido pelo melhoramento genético na cultura do arroz de terras altas, no período de 1950 a 2001. Foram feitos quatro experimentos de campo, nas localidades: Aeroporto e Agronomia, em Viçosa, MG; e nas Fazendas Capivara e Palmital, em Santo Antônio de Goiás, GO, e Goianira, GO, respectivamente. Os experimentos foram realizados no delineamento de blocos ao acaso, com três repetições. Avaliaram-se 25 cultivares, desenvolvidas no período de 1950 a 2001 . Foram coletados e analisados os dados referentes à produtividade de grãos, altura das plantas e dias para a floração. A fim de se obter estimativa mais precisa do ganho genético, optou-se por dividir as cultivares nos grupos precoce e tardio. Para a obtenção da estimativa do progresso genético, foi realizada a regressão linear das médias das cultivares por década de lançamento. Os ganhos genéticos para a produtividade de grãos foram de 0,3 e 2,09\% ao ano, nos grupos precoce e tardio, respectivamente. A altura média das plantas das cultivares reduziu-se em $21 \mathrm{~cm}$ no grupo precoce e em $38 \mathrm{~cm}$ no tardio, no período avaliado. Houve acréscimo médio de dez dias no ciclo, no grupo de cultivares precoce, e decréscimo de 13 dias no grupo tardio.
\end{abstract}

Termos para indexação: Oryza sativa, ganho genético, avaliação de genótipos, melhoramento genético.

\section{Genetic progress of upland rice between 1950 and 2001}

\begin{abstract}
The objective of this study was to quantify the genetic progress obtained by the genetic improvement of upland rice from 1950 to 2001. Four field experiments were conducted in the sites: Airport and Agronomy, in Viçosa, MG; in the farms Capivara and Palmital, in Santo Antônio de Goiás, GO, and Goianira, GO, respectively. The experiments were installed in a randomized block design, with three replications. Twenty-five cultivars planted in the period from 1950 to 2001 were assessed. Data of grain yield, plant height and days to flowering were collected and analyzed. In order to get the most accurate estimate of the genetic gain, the plants were separated in the groups of early and late cultivars. To estimate the genetic progress, a linear regression of the cultivar means per decade of use was performed. Genetic gains for grain yield were 0.3 and $2.09 \%$ per year in the early and late groups, respectively. Over the evaluated period, the mean plant height of the cultivars was reduced by $21 \mathrm{~cm}$ in the early group, and $38 \mathrm{~cm}$ in the late group. There was mean increase of ten days in the cycle of the early cultivar group and a decrease of 13 days of the late group.
\end{abstract}

Index terms: Oryza sativa, genetic gain, genotype evaluation, genetic improvement.

\section{Introdução}

O aumento da produção de alimentos está relacionado à manipulação de características genéticas das diferentes espécies vegetais (Borém, 2001). O desenvolvimento de novas cultivares, por meio do melhoramento de plantas, tem sido a base de sustentação da agricultura moderna (Bueno et al., 2001).

O melhoramento genético tem papel fundamental na viabilização das culturas, mediante o desenvolvimento de cultivares adaptadas à cada região. A avaliação da eficiência de um programa de melhoramento tem como um dos objetivos a definição das novas estratégias a serem seguidas, a fim de que cada unidade de recurso investido resulte no máximo de ganho possível. Para se determinar essa eficiência, diversos trabalhos foram feitos para estimar o ganho genético obtido pelos programas de melhoramento.

O progresso genético obtido pelo programa de melhoramento de arroz irrigado, desenvolvido em Minas 
Gerais (Santos et al., 1997), no período de 1974 a 1996, foi de $6,06 \%$ ao ano, na primeira fase, compreendida entre os anos agrícolas 1974/1975 e 1979/1980, e de $0,25 \%$ na segunda fase, representada pelos anos agrícolas 1980/1981 a 1995/1996. O grande progresso obtido na primeira fase resultou, fundamentalmente, da substituição de cultivares tradicionais por outras melhoradas, mais produtivas. As cultivares da segunda fase representam o fruto do melhoramento dedicado à qualidade de grãos e às resistência às enfermidades.

O ganho genético obtido pelo programa de melhoramento do arroz de terras altas, desenvolvido em Minas Gerais, no período de 1974/1975 a 1994/1995, foi de $1,26 \%$ ao ano, nas cultivares precoces, e de 3,37\% ao ano nas de ciclo médio (Soares et al., 1999). O arroz irrigado desenvolvido na região Meio-Norte do Brasil obteve ganho genético anual de $0,3 \%$, no período de 1983 a 1987 (Rangel et al., 2000). Ganhos genéticos anuais de 3,02\% na produtividade do arroz de várzea úmida, no Estado do Amapá, foram estimados por Atroch $\&$ Nunes (2000). Breseghello et al. (1999) relatam que foi baixo o ganho genético para rendimento de grãos do arroz irrigado, no Nordeste do Brasil, no período de 1984 a 1993. Em grande parte, isto se deve ao fato de o melhoramento genético ter sido direcionado para a obtenção de melhor qualidade de grãos das cultivares, em que se alcançaram ganhos genéticos consideráveis.

O objetivo deste trabalho foi quantificar o progresso genético obtido pelo melhoramento na cultura do arroz de terras altas, no período de 1950 e 2001.

\section{Material e Métodos}

Foram utilizadas 25 cultivares melhoradas, desenvolvidas pelos programas de melhoramento genético do arroz de terras altas do Brasil, durante o período compreendido entre 1950 e 2001 . Foram selecionadas as cultivares mais utilizadas em lavouras nas décadas de estudo. A cultivar CNAs8983, que se encontrava em avaliação de valor de cultivo e uso, por ocasião da condução do presente trabalho, foi incluída como representante das linhagens-elite (Tabela 1).

Foram realizados quatro experimentos de campo, durante o ano agrícola 2001/2002, nas localidades Aeroporto e Agronomia, da Universidade Federal de Viçosa, em Viçosa, MG; e nas Fazendas Capivara e Palmital, da Embrapa Arroz e Feijão, em Santo Antônio de Goiás, GO, e Goianira, GO, respectivamente. Os

Tabela 1. Genealogia e década de utilização das cultivares de arroz estudadas.

\begin{tabular}{|c|c|c|}
\hline Cultivar & Cruzamento & Década \\
\hline Pratão & Cultivar tradicional & Antes de 1960 \\
\hline Pérola & Cultivar tradicional & Antes de 1960 \\
\hline Amarelão & Cultivar tradicional & Antes de 1960 \\
\hline Bico Ganga & Cultivar tradicional & Antes de 1960 \\
\hline Batatais & Cultivar tradicional & Antes de 1960 \\
\hline Dourado Precoce & Seleção massal dentro do Douradão & De 1960 a 1970 \\
\hline Pratão Precoce & Seleção massal dentro do Pratão & De 1960 a 1970 \\
\hline IAC 1246 & Pratão/Pérola & De 1960 a 1970 \\
\hline IAC 25 & Dourado Precoce/IAC 1246 & De 1970 a 1980 \\
\hline IAC 47 & IAC 1246/IAC 1391 & De 1970 a 1980 \\
\hline IAC 165 & Dourado Precoce/IAC 1246 & De 1970 a 1980 \\
\hline IAPAR 9 & IAC F-3-7/Batatais & De 1980 a 1990 \\
\hline Rio Paranaíba & IAC $47 / 63-83$ & De 1980 a 1990 \\
\hline Guarani & IAC $25 / 63-83$ & De 1980 a 1990 \\
\hline Araguaia & IAC 47/TOS 2578/7-4-2-3-B2 & De 1980 a 1990 \\
\hline Xingu & IAC 47/IRAT 13 & De 1980 a 1990 \\
\hline Caiapó & IRAT 13/Beira Campo//CNAx104/Pérola & De 1990 a 2000 \\
\hline Canastra & TOX 939-107-2-101-1B/(Colombia 1xM 312A)//TOX 1780-2-1-1P-4 & De 1990 a 2000 \\
\hline Primavera & IRAT 10/LS 85-158 & De 1990 a 2000 \\
\hline IAC 202 & Lebonet/IAC25 & De 1990 a 2000 \\
\hline Carajás & IREM 293-B/IAC 81-176 & De 1990 a 2000 \\
\hline Bonança & СТ 7244-9-2-1-52-1/CT 7232-5-3-7-2-1P//CT 6196-33-11-1-3-AP & Depois de 2000 \\
\hline Carisma & СТ 72244-9-1-5-3/СТ 6196-33-11-1-3//CT 6946-2-5-3-3-2-M & Depois de 2000 \\
\hline Soberana & Cuiabana/CNAx 1235-8-3//CNA 6673 & Depois de 2000 \\
\hline CNAs 8983 & Keybonnet/CNA 7119 & Depois de 2000 \\
\hline
\end{tabular}


experimentos foram realizados no delineamento de blocos ao acaso, com três repetições de 25 tratamentos cada. A parcela experimental foi constituída de cinco fileiras de $5 \mathrm{~m}$ de comprimento, espaçadas $0,5 \mathrm{~m}$ entre si, das quais as três linhas centrais foram consideradas como área útil na colheita, tendo-se eliminado $0,5 \mathrm{~m} \mathrm{em}$ suas extremidades.

Os experimentos foram conduzidos no sistema de cultivo de sequeiro; no preparo do solo, foram utilizadas as práticas convencionais de uma aração e duas gradagens, de acordo com as necessidades do terreno, exceto na estação experimental da Fazenda Capivara, onde foi utilizado o sistema de plantio direto. A semeadura foi feita na primeira quinzena de dezembro de 2001, em todas as localidades, tendo-se utilizado entre 55 e 60 sementes por metro de sulco. As áreas utilizadas nos experimentos já eram cultivadas e, portanto, não necessitaram de adubações de correção. $\mathrm{Na}$ adubação de semeadura, utilizaram-se $400 \mathrm{~kg} \mathrm{ha}^{-1}$ da fórmula 4-14-8 e, aos 40 dias, como adubação de cobertura, foram aplicados $40 \mathrm{~kg} \mathrm{ha}^{-1}$ de nitrogênio, tendo-se utilizado como fonte o sulfato de amônio.

O controle de plantas daninhas foi realizado mediante capinas manuais, em número variável, de acordo com a necessidade de cada localidade, para manter as plantas de arroz livres da concorrência das invasoras. Com o objetivo de se determinar a suscetibilidade ou tolerância das cultivares às enfermidades, não se efetuou o controle de doenças em nenhuma das localidades. Quanto às pragas, detectou-se a incidência de Spodoptera frugiperda, no ensaio realizado na estação experimental da Agronomia, controlada com uma pulverização de clorpirifós, na dosagem de $750 \mathrm{~mL} \mathrm{ha}^{-1}$.

As parcelas foram colhidas manualmente, em função do ciclo de cada cultivar, e os grãos trilhados foram secados até atingirem 13\% de umidade, e beneficiados, em seguida, para a eliminação das impurezas e posterior pesagem. Foram avaliadas, na área útil das parcelas: a produtividade de grãos $\left(\mathrm{kg} \mathrm{ha}^{-1}\right)$; a altura das plantas $(\mathrm{cm})$, obtida pela medida de dez plantas ao acaso na parcela, quando estas apresentavam a panícula totalmente exposta; e dias corridos da emergência à floração de $50 \%$ das plantas da parcela.

Para a análise de variância, as cultivares foram agrupadas em precoces (floração até 90 dias) e tardias (floração acima de 90 dias), em razão da grande diversidade entre as cultivares avaliadas, no que se refere ao ciclo vegetativo, $\mathrm{e}$ na regressão linear, as décadas foram utilizadas como variável independente, e os caracteres foram medidos como variável dependente.

$\mathrm{O}$ fato de os experimentos terem estado totalmente dependentes das precipitações pluviais pode ter favorecido ou prejudicado mais intensamente um desses grupos. Por isso, as análises foram realizadas separadamente, por grupo.

Para a obtenção da estimativa do progresso genético do rendimento de grãos e das características dias para floração e altura de plantas, foi realizada a regressão linear das médias das variedades por década de utilização, com procedimentos semelhantes aos utilizados por Barbosa Neto et al. (2000), Mellado Zambrano (2000) e Alves et al. (2001). Todas as análises foram feitas com o auxílio do programa GENES (Cruz, 2001).

\section{Resultados e Discussão}

Pelos resultados das análises de variância, verificaram-se diferenças significativas entre os cultivares, para os caracteres: produtividade de grãos; dias para a floração; e altura das plantas.

O ganho genético foi estimado separadamente nas cultivares precoces e nas de ciclo tardio, pela ampla variabilidade genética presente nas cultivares avaliadas. No grupo precoce, observou-se redução na produtividade de grãos, ao se passar da década de 50 para a de 60. Essa redução ocorreu, em grande parte, pelo fato de as cultivares Dourado Precoce e Pratão Precoce, que foram as mais plantadas naquela década, terem apresentado, nos experimentos, suscetibilidade ao acamamento, o que provocou alta porcentagem de esterilidade das espiguetas e baixo índice de colheita e, por conseguinte, redução em sua produtividade.

Comparando-se os grupos precoces e tardios, foram observadas vantagens significativas das cultivares precoces em três ambientes. No experimento da Agronomia, no entanto, as cultivares precoces e tardias apresentaram, em média, produções semelhantes. Essa maior produtividade do grupo precoce se deve, em parte, ao fato de essas cultivares terem sido favorecidas pela melhor distribuição das chuvas, na maior parte das fases de desenvolvimento, principalmente no final do enchimento de grãos. Essa situação é freqüentemente observada em cultivares precoces, por permanecerem menos tempo no campo.

De forma geral, no grupo precoce, as cultivares mais produtivas foram as cultivadas comercialmente, a partir da década de 80 , à exceção do ensaio na estação experimental da Agronomia, em que a cultivar mais 
produtiva foi a IAC 165, lançada na década de 70 . Entretanto, as cultivares de pior desempenho foram as cultivadas antes da década de 70 .

No grupo tardio, o desempenho das cultivares foi similar ao do grupo precoce, com exceção do ensaio na estação experimental da Fazenda Palmital, em que a cultivar de melhor desempenho foi IAC 1246, lançada na década de 60 . No que se refere às cultivares de pior desempenho, todas pertenciam à década de 50 .

A partir da década de 60 até a de 80 , os incrementos no rendimento de grãos foram consideráveis, uma vez que os esforços estavam concentrados em aumentar a produtividade e o nível de resistência às pragas, doenças e outros estresses (Breseghello \& Stone, 1998). Com essas prioridades, foram liberadas várias cultivares, entre as quais as mais plantadas foram IAC 25, IAC 165 , IAPAR 9 e Guarani, que possuem baixa porcentagem de grãos estéreis e maior peso de grãos, que são componentes principais da produção. Cabe salientar que o arroz de terras altas, a partir de meados da década de 80, sofreu intensa concorrência do arroz longo fino (agulhinha), produzido em várzeas com irrigação por inundação controlada. Assim, as linhagens selecionadas a partir desse período não tiveram a mesma pressão de seleção, no que se refere à produtividade de grãos, uma vez que aquelas que possuíam grãos tipo agulhinha eram selecionadas, em detrimento de maior potencial produtivo (Santos et al., 1997; Rangel et al., 2000). Nesse contexto, o melhoramento genético tem obtido progressos consideráveis, com a liberação de cultivares que possuem excelente qualidade de grãos como Primavera e Carisma (Soares et al., 1999).

No grupo tardio, o incremento da produtividade foi crescente nas seis décadas de estudo, com exceção da de 70, quando houve decréscimo no rendimento. Dessa década, participou somente a cultivar IAC 47, que apresentou reduzida capacidade de perfilhamento e alta porcentagem de esterilidade, além de baixa estabilidade de produção nos locais avaliados. À semelhança do ocorrido com as cultivares do grupo precoce, a pesquisa foi eficiente em identificar cultivares que agregassem potencial de rendimento de grãos a outras características de interesse. Nesse sentido, as cultivares Caiapó, Canastra e Carisma estão entre as mais produtivas e possuem grãos de qualidade semelhante ao tipo agulhinha do arroz irrigado.

Os coeficientes de determinação significativos $\left(\mathrm{R}^{2}=0,53, \mathrm{p}<0,05\right.$ e $\left.\mathrm{R}^{2}=0,72, \mathrm{p}<0,05\right)$, nos grupos precoce e tardio, respectivamente, obtidos da análise de regressão para a característica produtividade de grãos, indicam ajustamento regular dos dados à equação (Figura 1).

Analisando-se a variação da produtividade média por décadas, percebeu-se que a partir da década de 90 , no grupo precoce, ocorreu ligeiro decréscimo do rendimento médio das cultivares, provocado, principalmente, pela exigência do consumidor por um produto de melhor qualidade (Breseghello \& Stone, 1998). As cultivares do grupo tardio, apesar de terem apresentado menores médias de produção que as do grupo precoce, expressaram ganho genético maior.

Comparando-se a média geral de produtividade de grãos das cultivares precoces, que foi de $3.731 \mathrm{~kg} \mathrm{ha}^{-1}$ (Tabela 2), com a média das cultivares tardias (2.859 $\left.\mathrm{kg} \mathrm{ha}^{-1}\right)$, verificou-se diferença de $832 \mathrm{~kg} \mathrm{ha}^{-1} \mathrm{a}$ favor do grupo precoce. Considerando-se que é esperado maior potencial de produtividade do grupo de cultivares de ciclo tardio, esses resultados são contraditórios, influenciados em grande parte pelo fato de as cultivares do grupo precoce terem sido menos prejudicadas pelas deficiências hídricas no final do ciclo.

O progresso genético, no período envolvido no estudo (década de 50 a 2000), foi de $146,6 \mathrm{~kg} \mathrm{ha}^{-1}$ por década, o que resultou em ganho de $14,6 \mathrm{~kg} \mathrm{ha}^{-1} \mathrm{ano}^{-1}(0,4 \%$ ao ano) no grupo precoce. No grupo tardio, o ganho foi de $276,8 \mathrm{~kg} \mathrm{ha}^{-1}$ por década e gerou ganho de $27,6 \mathrm{~kg} \mathrm{ha}^{-1} \mathrm{ano}^{-1}$ (1,6\% ao ano), resultados esses inferiores aos obtidos por Soares et al. (1999), que encontraram no programa

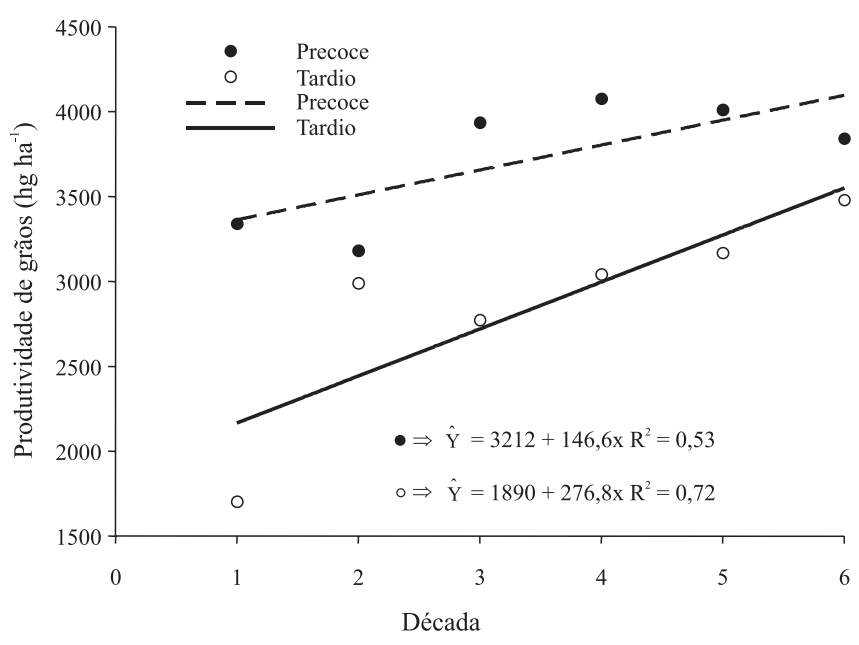

Figura 1. Progresso genético da produtividade de grãos, obtido pelo melhoramento do arroz de sequeiro para os grupos precoce e tardio, entre as décadas de 50 e 2000. 
de melhoramento genético de arroz de terras altas, desenvolvido em Minas Gerais, no período de 1974/1975 a 1994/1995, ganhos genéticos de 1,26\% para as cultivares precoces, e de 3,37\% para os genótipos de ciclo médio. Outros trabalhos vêm demonstrando reduzidos ganhos, nos diferentes programas de melhoramento do arroz. Ao avaliar o programa de melhoramento genético do arroz irrigado no Nordeste do Brasil, Breseghello et al. (1999) notaram que ocorreram ganhos de produtividade de $0,77 \%$ ao ano. Ao analisar o programa de melhoramento conduzido no Meio-Norte do Brasil, Rangel et al. (2000) detectaram ganho médio de $0,50 \%$ por ciclo para produtividade, e ganho médio anual ainda menor de $0,30 \%$. Santos et al. (1997) estimaram ganho para produtividade de $0,25 \%$ ao ano, ao avaliar o programa de melhoramento de arroz irrigado de Minas Gerais de 1980/1981 a 1995/1996, fase

Tabela 2. Médias de produtividade de grãos $\left(\mathrm{kg} \mathrm{ha}^{-1}\right)$ de arroz, nos ensaios instalados no Aeroporto e na Agronomia, em Viçosa, MG, e nas Fazendas Capivara e Palmital, em Santo Antônio de Goiás, GO, e Goianira, GO, respectivamente, em $2001 / 2002^{(1)}$.

\begin{tabular}{|c|c|c|c|c|c|}
\hline Cultivar & Aeroporto & Agronomia & Capivara & Palmital & Média \\
\hline & & & Precoces & & \\
\hline Amarelão & $5.291 \mathrm{~b}$ & $3.730 \mathrm{a}$ & $1.524 b$ & $3.344 \mathrm{a}$ & 3.472 \\
\hline Batatais & $4.932 b$ & $3.198 \mathrm{a}$ & $1.648 \mathrm{~b}$ & $3.055 \mathrm{a}$ & 3.208 \\
\hline Dourado Precoce & $5.695 \mathrm{a}$ & $3.730 \mathrm{a}$ & $1.395 b$ & $2.753 a$ & 3.393 \\
\hline Pratão Precoce & $4.645 b$ & $2.800 \mathrm{a}$ & $1.986 \mathrm{~b}$ & $2.443 a$ & 2.968 \\
\hline IAC 25 & $6.163 \mathrm{a}$ & $4.072 \mathrm{a}$ & $1.809 \mathrm{~b}$ & $3.306 \mathrm{a}$ & 3.837 \\
\hline IAC 165 & $6.011 \mathrm{a}$ & $4.742 \mathrm{a}$ & $2.085 b$ & $3.290 \mathrm{a}$ & 4.032 \\
\hline IAPAR 9 & $6.078 \mathrm{a}$ & $3.737 \mathrm{a}$ & $2.557 \mathrm{a}$ & $3.519 \mathrm{a}$ & 3.973 \\
\hline Guarani & $5.919 \mathrm{a}$ & $3.673 \mathrm{a}$ & $3.420 \mathrm{a}$ & $3.706 \mathrm{a}$ & 4.179 \\
\hline Primavera & $6.762 \mathrm{a}$ & $3.386 \mathrm{a}$ & $1.874 \mathrm{~b}$ & $3.553 \mathrm{a}$ & 3.894 \\
\hline Carajás & $6.605 \mathrm{a}$ & $4.410 \mathrm{a}$ & $1.721 \mathrm{~b}$ & $3.770 \mathrm{a}$ & 4.126 \\
\hline Bonança & $6.000 \mathrm{a}$ & $3.745 \mathrm{a}$ & $1.942 b$ & $4.271 \mathrm{a}$ & 3.989 \\
\hline Soberana & $6.030 \mathrm{a}$ & $2.966 \mathrm{a}$ & $1.552 \mathrm{~b}$ & $2.994 \mathrm{a}$ & 3.385 \\
\hline CNAs 8983 & $6.566 \mathrm{a}$ & $3.863 \mathrm{a}$ & $2.757 \mathrm{a}$ & $3.413 \mathrm{a}$ & 4.150 \\
\hline \multirow[t]{2}{*}{ Média } & $5.899 \mathrm{~A}$ & $3.696 \mathrm{~A}$ & $2.021 \mathrm{~A}$ & $3.340 \mathrm{~A}$ & 3.739 \\
\hline & & & Tardias & & \\
\hline Pratão & $2.812 \mathrm{c}$ & $2.772 b$ & $471 b$ & $552 \mathrm{~b}$ & 1.652 \\
\hline Pérola & $1.965 \mathrm{c}$ & $3.950 \mathrm{a}$ & $517 \mathrm{~b}$ & $1.459 \mathrm{a}$ & 1.973 \\
\hline Bico Ganga & $2.147 \mathrm{c}$ & $2.432 b$ & $683 b$ & $668 \mathrm{~b}$ & 1.483 \\
\hline IAC 1246 & $4.658 \mathrm{~b}$ & $4.097 \mathrm{a}$ & $620 \mathrm{~b}$ & $2.582 \mathrm{a}$ & 2.989 \\
\hline IAC 47 & $4.518 b$ & $3.854 \mathrm{a}$ & $606 b$ & $2.115 \mathrm{a}$ & 2.773 \\
\hline Rio Paranaíba & $5.636 \mathrm{a}$ & $3.301 \mathrm{~b}$ & $1.195 b$ & $2.043 \mathrm{a}$ & 3.044 \\
\hline Araguaia & $5.637 \mathrm{a}$ & $2.888 b$ & $570 \mathrm{~b}$ & $2.420 \mathrm{a}$ & 2.879 \\
\hline Xingu & $6.022 \mathrm{a}$ & $3.929 \mathrm{a}$ & $683 b$ & $2.179 \mathrm{a}$ & 3.203 \\
\hline Caiapó & $5.949 \mathrm{a}$ & $4.143 a$ & $730 \mathrm{~b}$ & $2.185 \mathrm{a}$ & 3.251 \\
\hline Canastra & $6.154 \mathrm{a}$ & $3.750 \mathrm{a}$ & $951 b$ & $1.554 b$ & 3.102 \\
\hline IAC 202 & $6.279 \mathrm{a}$ & $3.473 a$ & $677 b$ & $2.176 a$ & 3.151 \\
\hline Carisma & $6.166 \mathrm{a}$ & $2.943 b$ & $2.270 \mathrm{a}$ & $2.541 \mathrm{a}$ & 3.480 \\
\hline Média & 4.829B & $3.461 \mathrm{~A}$ & $831 \mathrm{~B}$ & $1.873 \mathrm{~B}$ & 2.748 \\
\hline Média geral & 5.386 & 3.584 & 1.450 & 2.636 & 3.264 \\
\hline
\end{tabular}

posterior à substituição das cultivares tradicionais pelos modernos de porte baixo.

A floração média das cultivares do grupo precoce teve incremento de dez dias, a partir da década de 50 até a de 2000. Esse incremento no tempo necessário para floração média foi decorrente dos programas de melhoramento terem selecionado cultivares com floração média em torno de 85 a 90 dias, como indicado por Rangel et al. (2000), para evitar redução acentuada no ciclo das cultivares e não comprometer sua produtividade. A altura média dessas plantas teve redução de $21 \mathrm{~cm}$, nas seis décadas de estudo. Esse resultado, de certa forma, era esperado, já que os programas de melhoramento genético de arroz de terras altas selecionam linhagens de porte médio, para reduzir o acamamento comum nas cultivares antigas (Soares et al., 1999).

Pela Figura 2, pode-se observar o comportamento das cultivares quanto à característica dias para floração. Houve incremento de dez dias no ciclo do grupo precoce, no período avaliado, e no grupo tardio ocorreu decréscimo de 14 dias nesse mesmo período. Para a característica altura de planta, houve decréscimos de $29 \mathrm{~cm}$ no grupo precoce e de $42 \mathrm{~cm}$ no grupo tardio. Pode-se inferir que os programas de melhoramento do arroz de terras altas (IAC, Iapar, Epagri e Embrapa Arroz e Feijão) têm dado prioridade à redução da altura média das cultivares liberadas nas últimas décadas (Figura 3).

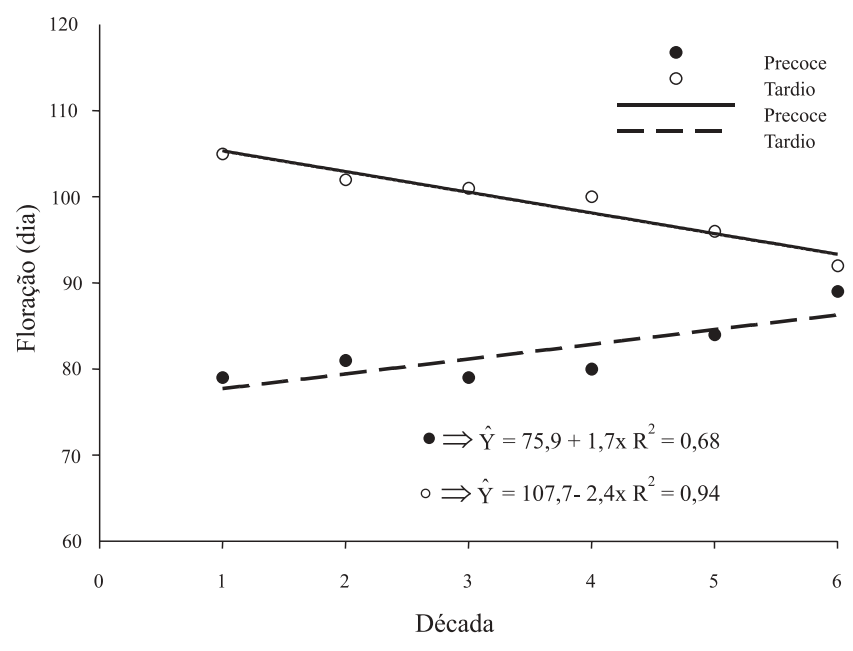

Figura 2. Progresso genético da floração (dias), obtido pelo melhoramento do arroz de sequeiro para os grupos precoce e tardio, entre as décadas de 50 e 2000. 


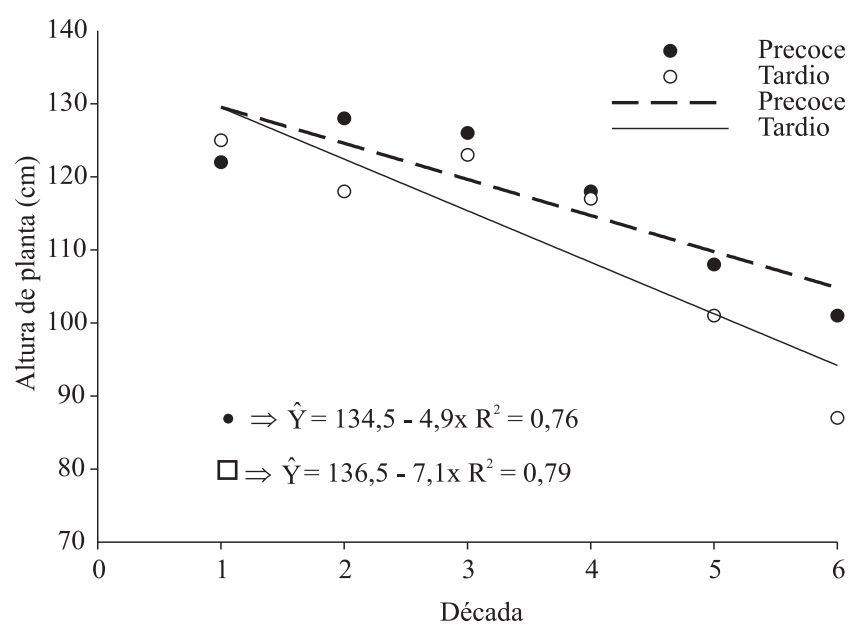

Figura 3. Progresso genético da altura de planta $(\mathrm{cm})$, obtido pelo melhoramento do arroz de sequeiro para os grupos precoce e tardio, entre as décadas de 50 e 2000.

\section{Conclusão}

A redução dos ganhos genéticos observados nos programas de melhoramento de arroz indica que novas alternativas de melhoramento devem ser empreendidas.

\section{Agradecimentos}

Ao Conselho Nacional de Desenvolvimento Científico e Tecnológico e à Universidade Federal de Viçosa.

\section{Referências}

AlVES, G.F.; RAMALHO, M.A.P.; ABREU, A. de F.B. Desempenho de cultivares antigas e modernas de feijão avaliadas em diferentes condições ambientais. Ciências Agrotécnicas, v.25, p.853869, 2001.
ATROCH, A.L.; NUNES, G.H. de S. Progresso genético em arroz de várzea úmida no Estado do Amapá. Pesquisa Agropecuária Brasileira, v.35, p.767-771, 2000.

BARBOSA NETO, J.F.; MATIELLO, R.R.; CARVALHO, F.I.F. de; OLIVEIRA, J.M.S.; PEGORARO, D.G.; SCHNEIDER, F.; SORDI, M.E.B.; VACARO, E. Progresso genético no melhoramento da aveia-branca no Sul do Brasil. Pesquisa Agropecuária Brasileira, v.35, p.1605-1612, 2000.

BORÉM, A. Melhoramento de plantas. 3.ed. Viçosa: UFV, 2001. $500 \mathrm{p}$.

BRESEGHELLO, F.; RANGEL, P.H.N.; MORAIS, O.P. de. Ganho de produtividade pelo melhoramento genético do arroz irrigado no Nordeste do Brasil. Pesquisa Agropecuária Brasileira, v.34, p.399407, 1999.

BRESEGHELLO, F.; STONE, L.F. (Ed.). Tecnologia para o arroz de terras altas. Santo Antônio de Goiás: Embrapa-CNPAF, 1998. $161 \mathrm{p}$.

BUENO, L.C.; MENDES, A.N.G.; CARVALHO, S.P. Melhoramento genético de plantas: princípios e procedimentos. Lavras: Ufla, 2001. 282p.

CRUZ, C.D. Programa Genes: versão Windows; aplicativo computacional em genética e estatística. Viçosa: UFV, 2001. 648p.

MELLADO ZAMBRANO, M.A. Mejoramiento de trigos harineros (Triticum aestivum L.) en la zona Centro Sur de Chile. II. Análisis del rendimiento y variables asociadas en trigos de primavera. Agricultura Técnica, v.60, p.32-42, 2000.

RANGEL, P.H.N.; PEREIRA, J.A.; MORAIS, O.P. de; GUIMARÃES, E.P.; YOKOKURA, T. Ganhos na produtividade de grãos pelo melhoramento genético do arroz irrigado no MeioNorte do Brasil. Pesquisa Agropecuária Brasileira, v.25, p.1595$1604,2000$.

SANTOS, P.G.; SOARES, P.C.; SOARES, A.A.; MORAIS, O.P. de; CORNÉLIO, V.M. de O. Estimativas do progresso genético do programa de arroz irrigado em Minas Gerais no período de 1974 a 1996. In: REUNIÃO DA CULTURA DO ARROZ IRRIGADO, 22., 1997, Balneário Camboriú. Anais. Itajaí: Epagri, 1997. p.27-30.

SOARES, A.A.; SANTOS, P.G.; MORAIS, O.P. de; SOARES, P.C.; REIS, M. de S.; SOUZA, M. de A. Progresso genético obtido pelo melhoramento de arroz de sequeiro em 21 anos de pesquisa em Minas Gerais. Pesquisa Agropecuária Brasileira, v.34, p.415424, 1999.

Recebido em 26 de setembro de 2006 e aprovado em 21 de dezembro de 2006 